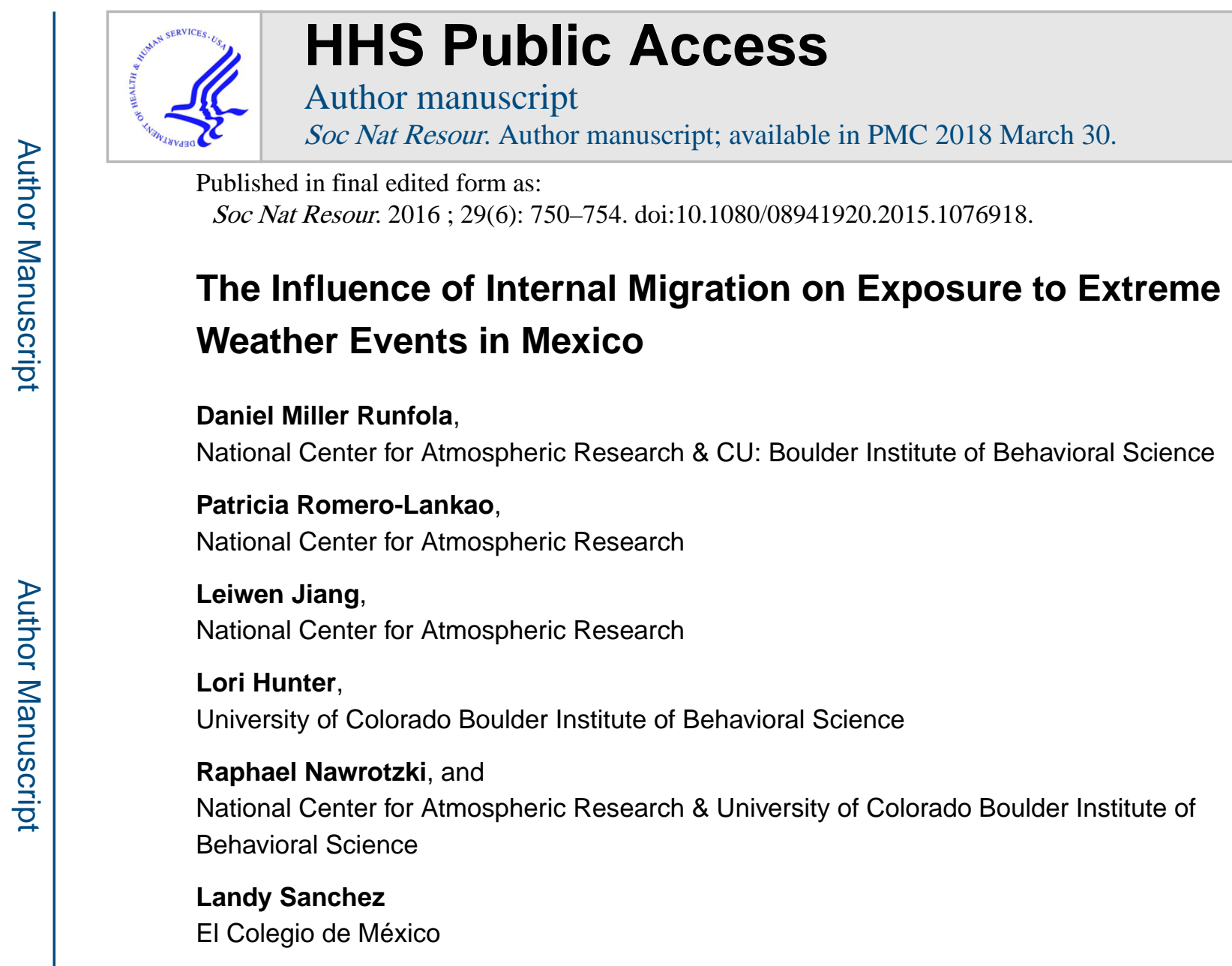

During the past half century, the number of individuals affected by natural disasters worldwide has sharply increased (Figure 1). Within countries, migration flows have resulted in substantial redistributions -- as of 2005, 763 million people were living outside their region of birth (UNDP 2013). The potential exists for redistribution to increase exposure to natural disasters if migration flows tend toward more vulnerable locations. The analyses in this Research Note are simple, but instructive. Mexican census micro data is used to estimate municipality-scale migration streams which are coupled with a disaster database (OSSO, 2013). We then contrast the total number of individuals exposed to natural disasters between $2005-2010$ to the total number of individuals that would have been exposed in the case of no migration.

\title{
Why Mexico?
}

Mexico provides an important case study due to both its long history of large-scale migration and its unique susceptibility to natural disasters and the potential impacts of climate change. Within Mexico, 6.3 million migrants ( $6 \%$ of the population) moved domestically during 2005-2010 (Ruggles et al. 2003). These high levels of migration are accompanied by a particular sensitivity to climate change, due to both the larger environmental impacts expected in sub-tropical areas (Boyd and Ibarrarán, 2009) and the socioeconomic vulnerability of many Mexicans (Eakin, 2005; Romero-Lankao et al., 2012). Hernandez et al. (2003) suggest that up to 39 percent of the Mexican territory to be under persistent drought conditions. Some climate scenarios project that areas in southern Mexico will effectively become unsuitable for rain-fed agriculture (Adamo and de Sherbinin, 2011). 
Data

Information on the municipality of residence for 2005 and 2010 for a $10 \%$ sample of individuals in Mexico (2010 census) is sourced from the Integrated Public Use Microdata Series (IPUMS 2011; also see Ruggles et al. [2003]). Census information is combined with data from the Disaster Inventory System ("DesInventar"; OSSO,2013) which provides details on disaster events across Caribbean and Latin American countries. In Mexico, these data - including the location, time and type of environmental event - are recorded at the municipality scale, allowing for detailed spatial analyses of disaster events. During our study timeframe, the "DesInventar" dataset provides information on 12 different classes of natural hazards (frosts, showers, gales, surges, droughts, heat waves, hail, thunder storms, floods, storms, flash floods, mud flows), of which floods are the most common $(45.7 \%$ of observations).

\section{Methods}

A four-step process is used to estimate the influence of migration on the number of individuals exposed to disasters in Mexico between 2005 - 2010. First, we tabulate the total number of disaster events between 2005 - 2010 within each municipality. Second, each municipality's population in 2010 is multiplied by the number of disaster events, providing an estimate of the maximum number of times residents could have been exposed to a disaster. Third, a hypothetical scenario of 2010 is created which represents the distribution of population within Mexico had no migration occurred between 2005 - 2010. Fourth, we repeat the multiplication procedure conducted in step 2 and contrast the results.

\section{Tabulating and Calculating Exposure}

The difference between the no migration scenario population and the observed population net migration from 2005 to 2010 - is shown in Figure 2a. As these figures illustrate, many of the municipalities which had negative net migration between 2005 - 2010 also had high levels of international migration.

\section{Scenario Comparison}

We compare overall exposure under the scenarios using both absolute and relative measures as illustrated in the equations below:

$$
\begin{gathered}
\mathrm{A}_{\mathrm{n}}=\mathrm{O}_{\mathrm{n}}-\mathrm{S}_{\mathrm{n}} \quad \text { equation } 1 \\
R_{n}=\frac{\left(O_{n}-S_{n}\right)}{O_{n}} \quad \text { equation 2 }
\end{gathered}
$$

where $n$ is a unique index for each municipality, $S_{n}$ is the estimated exposure (number of possible occurrence events) in the hypothetical no-migration scenario within municipality $n$, $O_{n}$ is the observed exposure, $A_{n}$ is the absolute contribution of migration to exposure 
(measured in possible occurrence events), and $R_{n}$ is the contribution of migration relative to the total observed exposure.

\section{Results}

Across the entire country, between $2005-2010$ migration resulted in approximately $1 \%$ fewer individual-level disaster exposures. While this value is small relative to the national population, it represents $\sim 2.6$ million fewer individual disaster exposures over the five year study window.

Figure $2 \mathrm{~b}$ reveals the absolute difference between exposure in the "no migration" scenario and the observed 2010 data. This map shows that: (1) migration streams from central-eastern Mexico to other destinations resulted in a decrease in exposure; (2) increased migration to very small, coastal municipalities frequently led to increases in exposure; and (3) in a few rare cases, coastal municipalities (such as Acapulco de Juarez) experienced a decrease in exposure attributable to migration. Figure $2 \mathrm{c}$ shows the relative contribution of migration to the observed exposure (the result of equation 2). This map shows a similar pattern to Figure $2 \mathrm{~b}$, identifying many small coastal "destination" municipalities as having an increased exposure, and large decreases throughout the central region

\section{Discussion}

Though the time frame analyzed here (2005-2010) is short, three patterns emerge. First, many of the most notable changes in environmental exposure at the nation-scale are occurring in cities. Second, some larger cities (i..e, Monterrey, Mexico City) are experiencing intra-boundary changes in exposure, possibly representing the impact of suburbanization. While suburbanization has been examined in terms of its environmental impacts (Runfola and Hankins, 2010; Runfola et al., 2013), the influence of suburbanization on disaster exposure has not been a topic of study. Third, decreases of population exposure in Acapulco de Juarez are potentially attributable to other factors, notably increasing drug violence (Chi et al., 2013), suggesting an understudied interplay between political instability, migration, and the environment.

\section{Study Limitations \& Future Directions}

This study has a number of limitations, suggesting useful extensions. First, the 5-year time frame is too short to generalize or extrapolate the findings more broadly. This is primarily driven by census data limitations. Second, the size and quality of data in our analytical units varies, resulting in variation in the spatial accuracy of our estimates of environmental disasters. Ongoing efforts by many organizations - including the Center for International Earth Science Information Network and Terra Populus - will soon allow for more refined analysis. Third, our approach discounts any changes in exposure for international migrants.

\section{Conclusion}

This brief Research Note (1) provided a methodological framework to examine the impact of migration on environmental exposure, (2) applied this methodology to Mexican domestic 
migration for 2005-2010, and (3) found that migration has resulted in a net decrease in environmental exposure within Mexico, though with a large degree of spatial variation. Across the entire country, migration resulted in a net decrease of 2.6 million exposures to environmental events, i.e. the number of times individuals would have experienced extreme weather between 2005 and 2010, though specific municipalities ranged from a 14\% increase in exposure to an $8 \%$ decrease. These results provide guidance for future case-study selection for more in-depth, driver-oriented studies - focusing on regions experiencing either sharp decreases or increases in exposure could highlight the potentially interconnected roles of economic/urban growth policy and household-scale migratory decisions in mitigating or amplifying the impacts of future climate change.

\section{Acknowledgments}

This research has benefited from research, administrative, and computing support provided by the University of Colorado Population Center (Project 2P2CHD066613-06), funded by the Eunice Kennedy Shriver National Institute of Child Health and Human Development. This manuscript has also benefitted from dialogue at the CUPC Conference on Climate Change, Migration and Health (NICHD project 5R13HD078101). The content is solely the responsibility of the authors and does not necessarily represent the official views of the CUPC or NIH.

\section{References}

Adamo, SB., de Sherbinin, A. In Population Distribution, Urbanization, Internal Migration and Development: An International Perspective. United Nations Department of Economic and Social Affairs; 2011. The impact of climate change on the spatial distribution of populations and migration; p. 161-195.

Boyd R, Ibarrarán ME. Extreme climate events and adaptation: an exploratory analysis of drought in Mexico. Environment and Development Economics. 2009; 14:371.

Chi, J., Hayatdavoudi, L., Kruszona, S., Rowe, B. master's thesis. UCLA; 2013. Reducing Drug Violence in Mexico: Options for Implementing Targeted Enforcement. http:// www.international.ucla.edu/media/files/Click-here-for-full-publication.-40-cz4.pdf

Eakin H. Institutional change, climate risk, and rural vulnerability: Cases from Central Mexico. World Development. 2005; 33:1923-1938.

Feng S, Krueger AB, Oppenheimer M. Linkages among climate change, crop yields and Mexico-US cross-border migration. Proceedings of the National Academy of Sciences. 2010; 107:1425714262.

Hernandez, CME., Torres, TL., Valdez, M. Sequia meteorologica. In: Gay, C., editor. Mexico: Una Vision Hacia el Siglo XXI. El Cambio Climatico en Mexico. Mexico City: UNAM Press; 2003. p. 15-27.

OSSO, C. [accessed 14 January 2014] DesInventar (Red de Estudios Sociales en Prevención de Desastres en América Latina - LA RED). 2013. http://www.desinventar.org/

Romero-Lankao P, Qin H, Hughes S, Haeffner M, Borbor-Cordova M. Urban Vulnerability and Adaptation to the Health Impacts of Air Pollution and Climate Extremes in Latin American Cities. Research in Urban Sociology. 2012; 12:247-275.

Ruggles S, King MD, Levinson D, McCaa R, Sobek M. IPUMS-International. Historical Methods. 2003; 36:60-65.

Runfola DM, Hankins KB. Urban Dereliction as Environmental Injustice. ACME: An International EJournal for Critical Geographies. 2010; 9:345.

Runfola DM, Polsky C, Nicolson C, Giner NM, Pontius RGJ, Krahe J, Decatur A. A Growing Concern?: Examining the influence of lawn size on residential water use in suburban Boston, MA, USA. Landscape and Urban Planning. 2013; 119:112-123.

United Nations Development Programme. [accessed 12 December, 2013] Poverty Reduction Migration. 2013. http://www.undp.org/content/undp/en/home/ourwork/povertyreduction/ focus_areas/focus_trade_and_investment/migration.html 


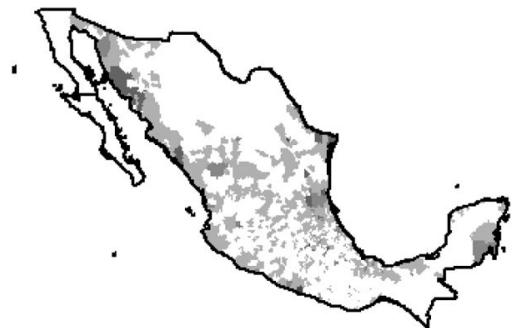

Total Number of Disasters

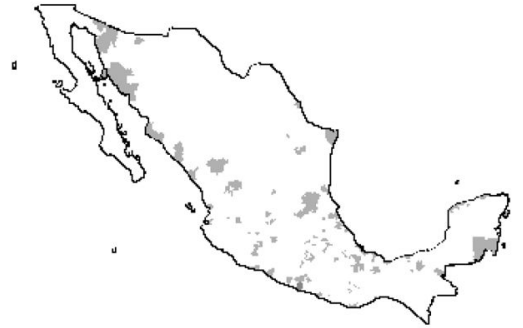

Number of Storms

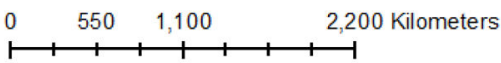

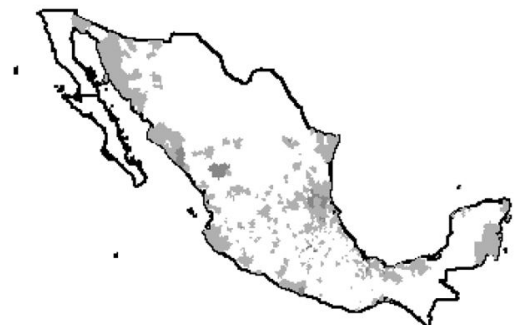

Number of Floods

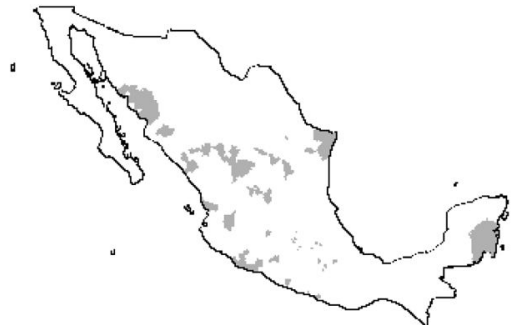

Number of Droughts

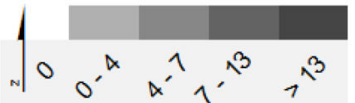

Figure 1.

The total number of hydro-meteorological disaster events, 2005-2010 (OSSO, 2013). 

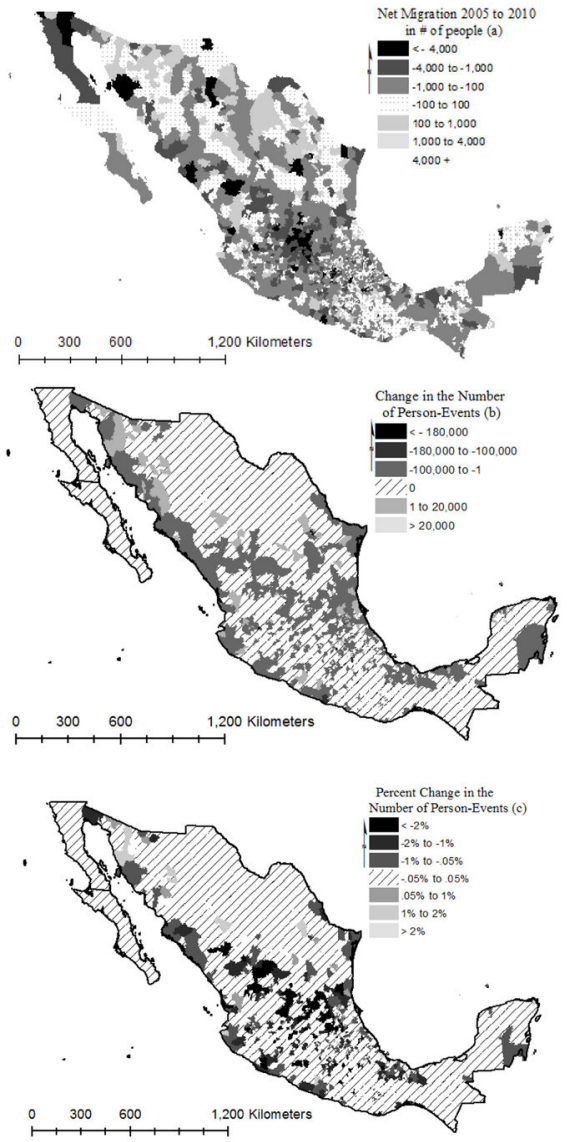

Figure 2.

Illustrates the interplay between migration and environmental exposure. 2a shows the net migration from 2005 to $2010,2 b$ the absolute contribution of migration to exposure measured in potential occurrence events (equation 1), and $2 \mathrm{c}$ the relative contribution of migration to exposure (equation 2). 